\title{
ADVÉRBIOS \\ E O MOVIMENTO \\ DO VERBO ${ }^{1}$
}

ADVERBIOS Y EL MOVIMIENTO DEL VERBO

ADVERBS AND VERB MOVEMENT

Aquiles Tescari Neto*

Universidade Estadual de Campinas

\begin{abstract}
RESUMO: Os advérbios têm sido utilizados em larga escala, em Gramática Gerativa, como diagnósticos para o movimento do verbo e de outros constituintes da oração, uma vez que ocupam posições rígidas e fixas na estrutura oracional. Com o avanço das pesquisas do Programa Cartográfico e consequente assunção de uma estrutura oracional enriquecida, é pertinente perguntar quais advérbios seriam de fato diagnósticos fidedignos para o movimento do verbo. O trabalho tem, então, por objetivo principal, valendo-se especialmente de dados do português brasileiro, mostrar a pertinência da utilização de advérbios baixos como testes para o movimento do verbo à flexão nessa língua. Será revisitada a literatura pertinente no intuito de mostrar por que advérbios baixos são bons diagnósticos à subida do verbo temático (tanto em sua forma finita, como no infinitivo, gerúndio e particípio). Num segundo momento, o trabalho apresentará argumentos contra a assunção de advérbios altos ou sentenciais como diagnósticos à subida do verbo em português do Brasil. Nessa língua, portanto, somente advérbios baixos podem ser tomados como diagnósticos, dado que os altos (ou sentenciais) não podem aparecer em posição sentencial final, independentemente da forma do verbo temático considerada.
\end{abstract}

PALAVRAS-CHAVE: Sintaxe Gerativa. Cartografia. Movimento do verbo. Advérbio, Diagnóstico.

RESUMEN: Los adverbios han sido utilizados en gran medida, en la Gramatica Generativa, como diagnósticos del movimiento del verbo y de otros constituyentes de la oración, ya que ocupan posiciones rígidas y fijas en la estructura de la oración. Con el avance de las investigaciones de la Cartografia sintáctica y, consecuentemente, al asumir una estructura de oración enriquecida, es pertinente preguntar qué adverbios ofrecerían diagnósticos fidedignos para el movimiento del verbo. Aprovechando especialmente los datos del portugués de Brasil, este trabajo evidencia la relevancia del uso de adverbios bajos como pruebas del movimiento del verbo a la flexión. Se consultan estudios pertinente con el fin de mostrar por qué los adverbios bajos son buenos diagnósticos de la subida del verbo temático (tanto en su forma finita, como en el infinitivo, gerundio y participio) en el portugués de Brasil. En un segundo momento, se presentan argumentos en contra de la idea de que adverbios altos o oracionales son diagnósticos a la subida del verbo en portugués de Brasil. En este idioma, por lo tanto, sólo los adverbios bajos pueden tomarse como diagnósticos, dado que los altos (o sentenciales) no pueden aparecer en posición sentencial final, independientemente de la forma del verbo temático considerado.

PALABRAS CLAVE: Sintaxis generativa. Cartografía. Movimiento del verbo. Adverbio. Diagnóstico.

\footnotetext{
${ }^{1}$ Agradeço a leitura de Francisco Forfero Pataquiva, Matthew Sant'Anna, Andrés Caraballo, Igor Pina, Jéssica Carola Lopes e Paola Padula, e os questionamentos levantados a uma primeira versão deste texto. Agradeço também aos participantes da mesa sobre cartografia sintática, no GT-TG (Florianópolis, junho de 2018) pelas questões apresentadas (sobretudo a Núbia Rech e a Luigi Rizzi). O trabalho se beneficiou sobremaneira das contribuições dos pareceristas da Forum Linguístico, com sua leitura atenta, críticas e sugestões. Naturalmente, se erros passaram despercebidos, a culpa é minha. Agradeço à FAPESP por apoiar a minha pesquisa (processo 2016/20853-6).

* LaCaSa - Laboratório de Cartografia Sintática: Pesquisa e Ensino (https://is.gd/LaCaSaUnicamp). Instituto de

EstudosdaLinguagem,UNICAMP. E-mail: tescari@iel.unicamp.br.
} 
ABSTRACT: In the Principles and Parameters Theory, adverbs have been widely used as diagnostics for V raising since they occupy rigid and fixed positions in the structure of the clause. The Cartographic Program - and the assumption of enriched structures for the sentence and its major phrases - brings about an important question regarding the place of adverbs in the theory of verb movement: which adverbs would indeed count as reliable diagnostics for verb raising? The main goal of this work is to present data supporting the view that low adverbs are bona fide diagnostics for verb raising to the inflectional domain in Brazilian Portuguese. The relevant literature will be revisited so as to show why low adverbs are good diagnostics for the movement of different forms of the thematic verb in this language. In addition to that, some arguments will be presented against the assumption of "high" sentence adverbs as diagnostics for verb raising in the language considered. Therefore, in Brazilian Portuguese only low adverbs can be taken as diagnostics for verb raising since high adverbs cannot appear in the sentence-final position, regardless of the verb form taken into consideration.

KEYWORDS: Generative Syntax. Cartography. Verb raising. Adverbs. Diagnostics.

\section{INTRODUÇÃO}

Em sintaxe gerativa, os sintagmas adverbiais (AdvPs) têm sido evocados como diagnósticos precisos para movimentos de constituintes, especialmente o verbo (V) temático e seus argumentos, pelo menos desde o trabalho de Pollock (1989) sobre a explosão da projeção de IP (o sintagma da flexão). Os AdvPs que Pollock considerou como “adjuntos de VP" (os advérbios "baixos", também denominados "left-edge adverbs" - como, por exemplo, os advérbios de modo (bem, cuidadosamente, etc.)) - têm, desde então, sido considerados diagnósticos fidedignos para o movimento do verbo à flexão, justamente por ocuparem uma posição muito próxima àquela onde o V é "gerado", podendo, assim, indicar se ele teria ou não deixado o sintagma verbal e se movido à flexão (cf., dentre (tantos) outros, POLLOCK, 1989; BELLETTI, 1990; GALVES, 1993, 1994; SILVA, 1996; COSTA, 1996, 1998; CINQUE, 1999, 2004; MODESTO, 2000; BRITO, 1999, 2001; SILVA, 2001; LAENZLINGER, 2002, 2011; LAENZLINGER; SOARES, 2005; SILVA, 2009; CYRINO, 2013; TESCARI NETO, 2013). Entende-se, então, por que a teoria gerativa tem dado importância capital aos adverbiais. ${ }^{2}$

Para além de sua importância no conjunto das discussões sobre a categoria dos advérbios em uma teoria formal e sua vinculação com o movimento de constituintes, o trabalho de Pollock (1989) foi de fundamental relevância para pelo menos outros dois grandes desenvolvimentos cruciais da teoria gerativa atual. Em primeiro lugar, para o debate sobre a natureza da flexão, seus átomos constituintes e a variação entre as línguas, discussão que ganha destaque anos mais tarde com o trabalho de Cinque (1997, 1999), em perspectiva translinguística, que, ao explodir o IP ainda mais, identificando as quase cerca de 30 categorias atômicas de modo, tempo e aspecto das mais variadas classes semânticas - conforme discutido na seção 3 - abriu caminho também para um resgate das discussões sobre os universais linguísticos de Greenberg, desta vez em perspectiva gerativista. Em segundo lugar, Pollock (1989) foi de fundamental importância para o debate sobre a natureza categorial dos quantificadores ditos flutuantes, bem como a sua integração à estrutura (se como advérbios ou como produto de encalhe pelo movimento de seu NP associado - cf. as discussões de Sportiche (1988), Bobaljik (1995, 2001), Doetjes (1997), Giusti (1991), Cardinaletti e Giusti (1991), Fitzpatrick (2006), Vicente (2006), Lacerda (2012, 2016), Vicente e Quadros Gomes (2013), Tescari Neto (2013), dentre tantos outros).

Seguindo a mesma linha de Pollock (1989), Cinque (1999) - ao reconhecer que o espaço IP seria constituído por cerca de 30 projeções, cada uma potencialmente hospedando um advérbio de importe semântico específico -inaugura um novo modo de abordar a questão da subida do V: quais dessas cerca de 30 classes de AdvPs posicionados em Especificadores (Spec) distintos poderiam ser consideradas diagnósticos fidedignos para o movimento do $\mathrm{V}$ ? Ao final do trabalho, deverá ficar claro que apenas os AdvPs ditos baixos i.e., os adjuntos de VP - como os advérbios de modo (bem, calmamente, cuidadosamente), por exemplo - podem ser tomados como diagnósticos para o movimento de $\mathrm{V}$ à flexão em português brasileiro (PB): o $\mathrm{V}$ temático não poder se mover à esquerda de AdvPs altos (ou sentenciais) nessa língua. Um mergulho na cartografia das estruturas sintáticas vai ao encontro,

\footnotetext{
2 Por vezes utilizarei o termo mais abrangente "adverbiais" pelo fato de, especialmente em Cinque (1999, 2004), não só os advérbios propriamente ditos (i.e., as formas terminadas em“-mente” em italiano e português; os sintagmas nominais hoje, ontem; os pronomes locativos aqui, ali, aí, o advérbio irrealis talvez, dentre outros comumente arrolados em gramáticas tradicionais na classe dos "advérbios"), como também qualquer sintagma (XP) que venha a desempenhar funções "adverbiais" - lexicalizando, assim, o conteúdo de uma das projeções funcionais da hierarquia apresentada mais adiante em (2), na seção 3 -, poderem ser utilizados como diagnósticos para o movimento do $\mathrm{V}$.
} 
portanto, do que já nas décadas de 80 e 90 se dizia sobre o uso de advérbios como diagnósticos para movimentos: AdvPs baixos/“de VP” são diagnósticos confiáveis (cf. POLLOCK, 1989; GALVES, 1994).

O trabalho se organiza da seguinte forma. Na seção 2, traço um breve histórico da categoria flexão, uma vez que está vinculada diretamente à subida do verbo. Na sequência, apresento as ideias gerais proposta de Cinque (1999), que constitui o nicho teórico que norteará as discussões do trabalho. Na seção 4, mostro por que, em PB, os advérbios baixos são diagnósticos fidedignos à subida do $\mathrm{V}$, independentemente de sua forma (V finito, infinitivo, gerúndio, particípio). Os advérbios altos, conforme veremos na seção 5 revisitando Tescari Neto (2015) -, não podem ser considerados diagnósticos em PB: não podem aparecer em posição sentencial final, nem são recuperáveis pelo VP elíptico em PB. Na seção 6, aparecem as considerações finais.

\section{BREVE HISTÓRICO SOBRE A CATEGORIA "FLEXÃO” E SUA VINCULAÇÃO COM O MOVIMENTO DO V}

A Sintaxe Gerativa já desde o seu início (cf. CHOMSKY, 1957) entende que a estrutura da oração não pode ser reduzida apenas a uma configuração envolvendo o sujeito e o predicado. Em Syntactic Structures, Chomsky (1957) já postulava uma posição entre o sujeito e o predicado para acomodar os verbos modais, os auxiliares, bem como a pouca flexão de que dispõe a morfossintaxe do $\mathrm{V}$ em inglês. Belletti (2001), ao traçar o histórico do tratamento dado à flexão na teoria gerativa, explica que, não obstante a inclusão, já em Syntactic Structures, de uma posição que acomodasse a flexão entre o sujeito e o predicado, os anos 60 e 70 teriam obscurecido seu papel, dada a prática comum de reduzir a representação da estrutura da oração à regra de reescrita padrão $[S \rightarrow N P V P]$, que não incluía uma posição para a flexão.

Foi somente com o advento da Teoria de Princípios e Parâmetros (CHOMSKY, 1981) que a flexão voltou a receber atenção pela gramática gerativa, sendo considerada a categoria mediadora da relação sujeito-predicado (BELLETTI, 2001). Determinou-se que o nó funcional da flexão portaria informações gramaticais de tempo, modo, aspecto e concordância. A estrutura da oração passou a ser esquematizada através da regra de reescrita da seguinte forma: $[S \rightarrow \mathrm{NP}$ Infl VP], tendo a categoria flexão (Infl) como mediadora da relação sujeito-predicado. Um importantíssimo passo ulterior foi dado com Chomsky (1986), por reconhecer que o esquema X' ("X barra") fosse estendido também às categorias funcionais da oração. A arquitetura da oração, tal qual assumida pelo Programa Minimalista (CHOMSKY, 1995), encontra suas raízes praticamente já na representação oferecida em Chomsky (1986), com uma projeção funcional para o complementador (CP), uma projeção para a flexão (IP), além da projeção lexical do verbo (VP), onde seriam atribuídos os papéis temáticos. Ulteriormente, o Programa Minimalista incorporou o sintagma $v \mathrm{P}$ à estrutura, originalmente proposto em Larson (1988).

A incorporação da flexão à estrutura da oração (com a teoria de Princípios e Parâmetros) desencadeou uma investigação mais precisa acerca de sua própria natureza, na segunda metade dos anos oitenta, que se estendeu pela década de 90. Essa investigação se deu, conforme Belletti (2001), em consequência de questionamentos conceituais e empíricos que começaram a aparecer nos debates sobre esta categoria. Em termos conceituais, indagou-se sobre a adequação da assunção de um núcleo único, Infl (inflection 'flexão'): como a teoria poderia lidar com o impasse gerado pela assunção deste único núcleo constituído, porém, por um conjunto de diferentes traços semânticos, quais, Tempo, Modo e Aspecto? De um ponto de vista empírico, a análise de Emonds (1978) sobre a posição do verbo em relação à negação voltou a ser debatida, desta vez em termos da subida do V à flexão. O artigo seminal de Pollock (1989), já citado, teve importante papel neste contexto, ao explicar que as diferenças entre o inglês e o francês, com respeito à colocação do $\mathrm{V}$ em relação a certos AdvPs e à negação, poderiam ser explicadas em termos do movimento do $V$ à flexão em francês, mas não em inglês. Os dados em (1), de Pollock (1989: 367) ilustram a questão, mais especificamente o posicionamento de V em relação ao AdvP baixo (i.e., adjunto de VP) often/souvent 'frequentemente'.

$\begin{array}{lll}\text { a. } & * \text { ohn } \quad \text { kisses } \quad \text { often } & \text { Mary } \\ \text { John beija } & \text { frequentemente } & \text { Mary } \\ \text { 'John beija frequentemente Mary' } & \end{array}$

'John beija frequentemente Mary' 


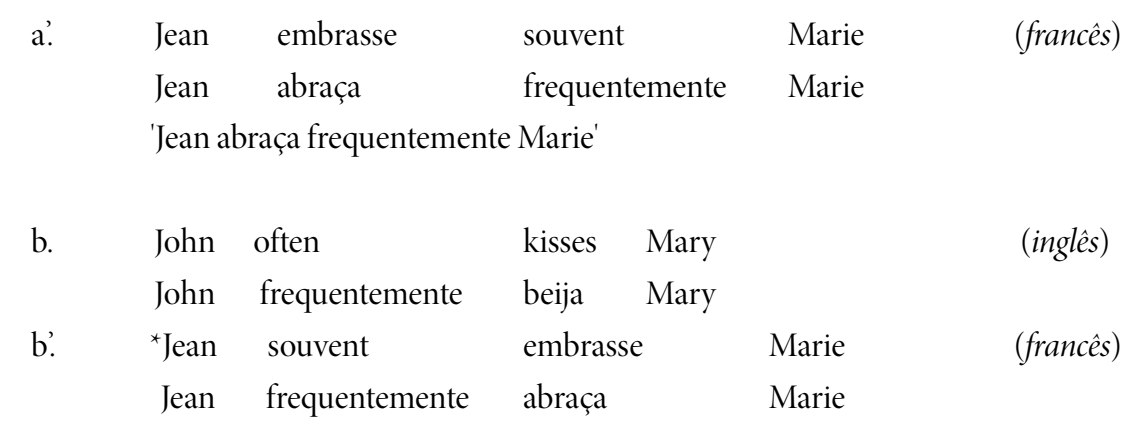

As sentenças em (1) sugerem - assumindo-se que o advérbio baixo often/souvent 'frequentemente' se adjunja a VP, por tomar por escopo o processo verbal - que o $\mathrm{V}$ temático necessariamente se move à flexão em francês (confrontar a agramaticalidade de (1b') com a gramaticalidade de (la')), mas não em inglês (cf. a agramaticalidade de (1a), que sugere o movimento do V, com a gramaticalidade de (1b), que sugere a permanência de $\mathrm{V}$ no domínio temático). As representações das derivações envolvendo as sentenças (1a'b') em (1), do francês, são apresentadas nas figuras 1 e 2, assumindo-se aqui uma representação pré-pollockiana de INFL, retomada no Programa Minimalista (CHOMSKY, 1995).

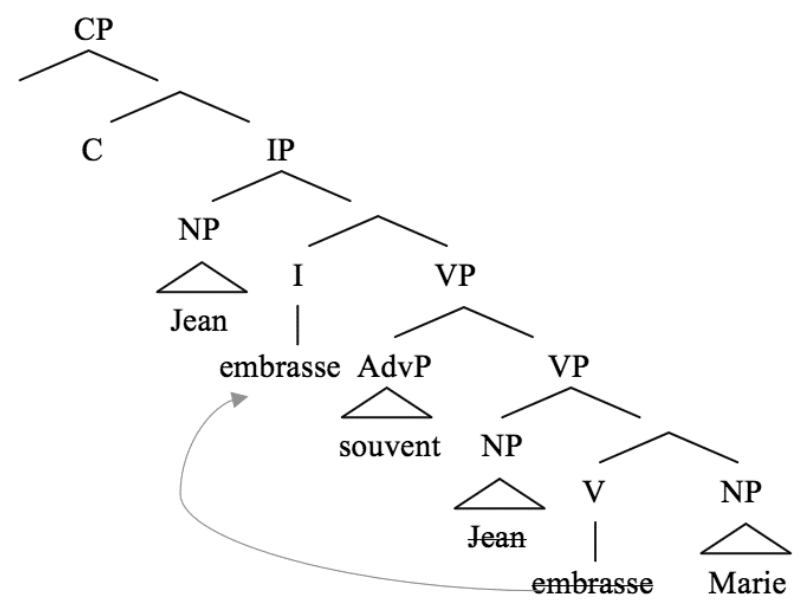

Figura 1: Representação de (1a')

Fonte: Elaboração própria

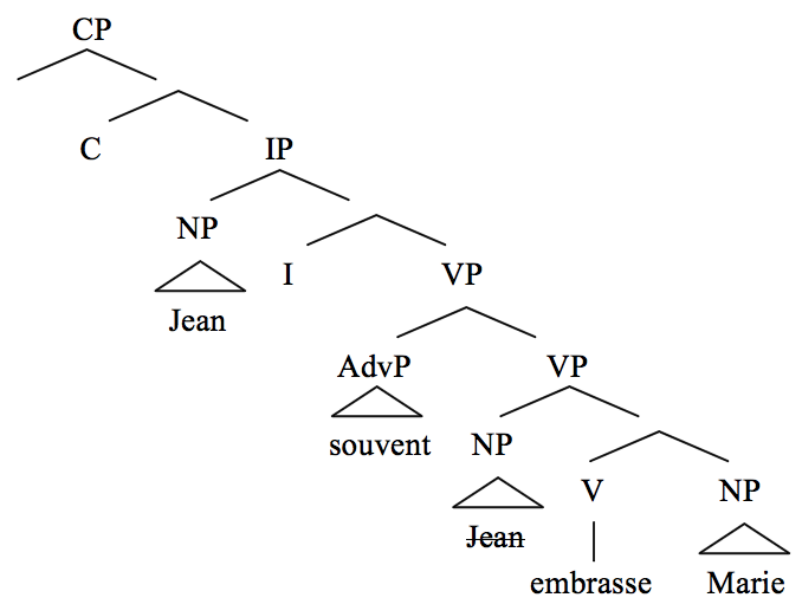

Figura 2: Representação de (1b')

Fonte: Elaboração própria

Se se aceita, portanto, a premissa pollockiana segundo a qual os AdvPs estão fixos na estrutura - premissa essa que recebe ulterior motivação empírica em Cinque (1999) -, há razão para aceitar como válida a utilização do posicionamento do V em relação a AdvPs 
como recurso diagnóstico para detectar o movimento do $\mathrm{V}$ à flexão ${ }^{3}$. Uma pergunta importante se coloca, tendo em vista as investigações cartográficas com ulterior enriquecimento das estruturas: se há, no Middlefield ou espaço IP, cerca de 30 projeções funcionais, cada uma potencialmente hospedando um AdvP em seu especificador, que advérbios utilizar como diagnósticos para o movimento do verbo? Conforme se verá nas próximas seções, a ideia de Galves $(1993,1994)$ de que o verbo se move a uma posição medial da flexão em PB será mantida. Será mantida também a premissa dessa autora segundo a qual, "Para que se possam encontrar provas a favor ou contra o movimento do verbo, deve-se observar o comportamento dos advérbios de modo, gerados em adjunção a uma projeção de V." (GALVES, 2001, p. 109). Antes, porém, de avançar no estudo do movimento do verbo e sua diagnose por meio dos advérbios da hierarquia universal, faz-se necessária uma breve apresentação do modelo cartográfico de Cinque (1999).

\section{DA CARTOGRAFIA DE CINQUE (1999): A HIERARQUIA UNIVERSAL DE ADVÉRBIOS}

Tendo em vista a distribuição relativa de advérbios de classes semânticas distintas, valendo-se de dados de línguas das mais diversas famílias, Cinque propôs que a "flexão" (o "IP” ou "TP" - também conhecido como Middlefield) seria constituído pelas seguintes categorias funcionais, realizadas ou não foneticamente via AdvPs, em Spec, ou núcleos funcionais (“X”s").

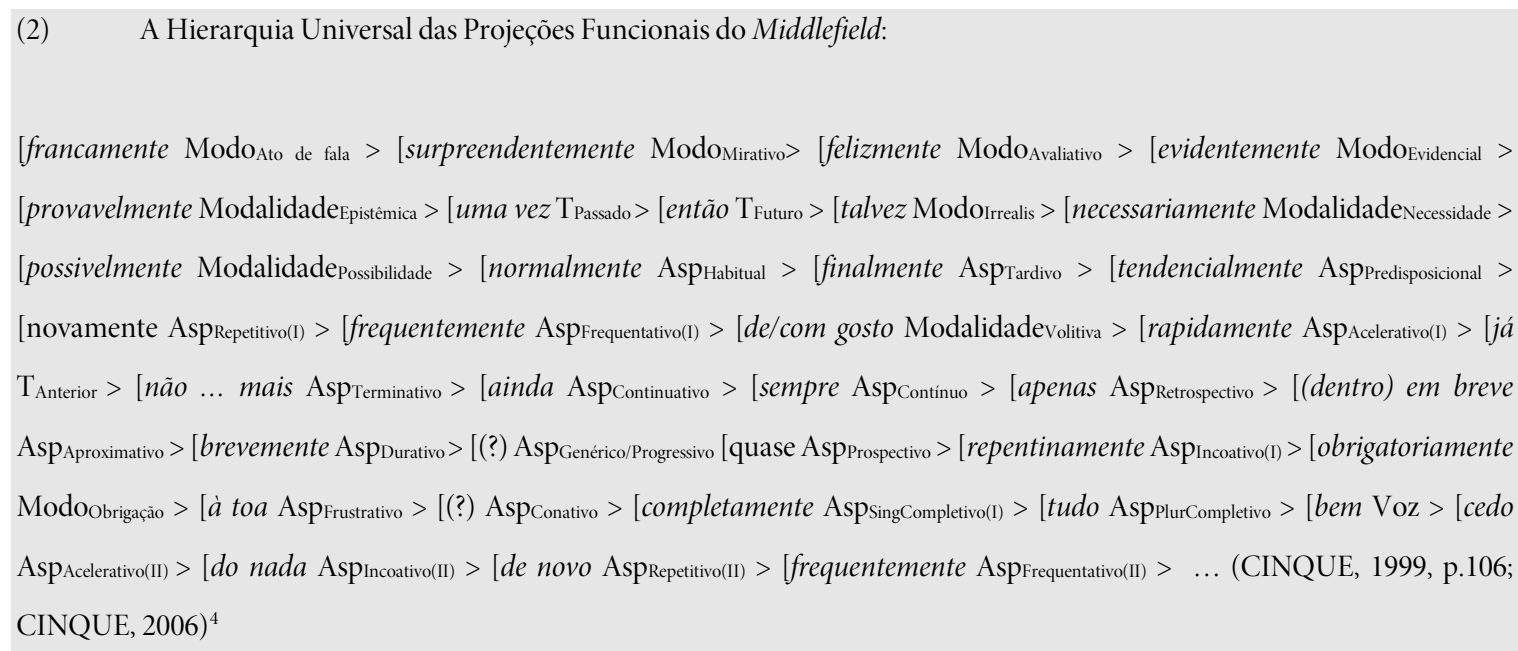

Cinque assume, com Pollock (1989), que os advérbios de (2), alocados em Spec distintos, ocupam posições fixas, a não ser que algum traço da estrutura informacional (Tópico, Foco, etc.) tenha de ser valorado, motivo pelo qual têm sido tradicionalmente utilizados como diagnósticos de movimentos.

Para chegar à hierarquia em (2), o autor vale-se de testes de precedências e transitividade envolvendo advérbios de classes semânticas distintas. Assim, se um dado $\mathrm{AdvP}_{\mathrm{A}}$ precede (“>”) um dado $\mathrm{Adv}_{\mathrm{B}}$, que precede, por sua vez, um $\mathrm{AdvP}_{\mathrm{C}}$, por transitividade inferese que o $\mathrm{AdvP}_{\mathrm{A}}$ precede o $\mathrm{AdvP}_{\mathrm{C}}$ :

$$
\begin{array}{lll}
\text { (3) } & \text { a. } & \operatorname{AdvP}_{\mathrm{A}}>\operatorname{AdvP}_{B} \\
\text { b. } & { }^{*} \operatorname{AdvP}_{\mathrm{B}}>\operatorname{AdvP}_{\mathrm{A}} \\
\text { (4) } & \text { a. } & \operatorname{AdvP}_{\mathrm{B}}>\operatorname{AdvP}_{\mathrm{C}}
\end{array}
$$$$
\text { b. } \quad{ }^{\star} \operatorname{AdvP}_{\mathrm{C}}>\operatorname{Adv}_{\mathrm{B}} \quad \text { (Portanto: } \operatorname{Adv}_{\mathrm{A}}>\operatorname{AdvP}_{\mathrm{B}}>\operatorname{Adv}_{\mathrm{C}} \text { ) }
$$

\footnotetext{
${ }^{3}$ Para além do teste envolvendo AdvPs, há ainda outros testes que têm sido igualmente utilizados para diagnosticar o movimento de V. Por exemplo, a sua posição em relação à negação e quantificadores flutuantes (cf. Galves, 1994; Silva, 1996; Modesto, 2000, dentre outros). Galves (1994) e Silva (1996) mostram que os quantificadores flutuantes não são decisivos como diagnósticos à subida do verbo em PB. Tescari Neto (2013), com argumentos independentes, também sugere que esse teste não é fidedigno (não apenas para o português, como também pelo menos em inglês). Por razões de espaço, não explicitamos essas razões aqui.

${ }^{4}$ Essa versão para o PB é baseada em Tosqui \& Longo (2004), Santana (2005, 2007) e Tescari Neto (2013).
} 
Os dados abaixo, em (5-6), ilustram essa metodologia cartográfica comumente utilizada na determinação de hierarquias: os testes de precedência e transitividade. Nessas sentenças, esse expediente se aplica a AdvPs do italiano. Assim, em (5), o AdvP de ato de fala francamente 'francamente' precede o AdvPs avaliativo purtroppo 'infelizmente'. Já em (6), o avaliativo purtroppo precede o epistêmico probabilmente 'provavelmente'. Por transitividade, conclui-se que francamente precede probabilmente, conforme a hierarquia em (2). Os dados em (5-6) são de Cinque (1999: 12).
AdvP ato de fala $>$ AdvP avaliativo
a. Francamente ho purtroppo una pessima opinione divoi
Francamente eu-tenho infelizmente uma péssima opinião de vocês
'Francamente eu infelizmente tenho uma péssima opinião sobre vocês'
b. * Purtroppo ho francamente una pessima
Infelizmente eu-tenho francamente uma péssima
opinione di voi
opinião sobre vocês

(6)

AdvP avaliativo $>$ AdvP epistêmico
a. Gianni ha perfortuna
Gianni tem felizmente
probabilmente
provavelmente
accettato
'Gianni felizmente provavelmente aceitou'
b. ${ }^{\star}$ Gianni ha probabilmente perfortuna accettato
Gianni tem provavelmente felizmente aceitado

O expediente aplicado a (5-6) - e aos demais AdvPs de (2) para determinar-lhes a ordem - é também estendido aos núcleos funcionais (de diversas línguas). (7), por exemplo, apresenta Vs ditos “auxiliares" em inglês (7a) e espanhol (7b) (cf. CINQUE, 1999: 57), os quais têm sido considerados categorias nucleares da Flexão:

$\begin{array}{lllllll}\text { a. } & \text { These books have been being read allyear } & \\ & \text { Esses livros têm estado sendo lidos todo ano } & \\ & \text { Esses livros têm sido lidos todo o ano' } & & \\ \text { b. } & \text { Esos libros han estado siendo leídos todo el año } \\ & \text { Esses livros têm estado sendo lidos todo o ano } \\ & \text { 'Esses livros têm sido lidos todo o ano' } & & & \end{array}$

Em (7), have 'ter' (a) e han (b) lexicalizam o núcleo de tempo; been (7a) e estado (7b), o aspecto perfeito; being (7a) e siendo (7b), o progressivo; o verbo lexical, dada a construção passiva, lexicaliza (derivacionalmente) a Voz (read, in (a) e leídos, em (b)). De (7), é possível inferir a seguinte ordenação parcial (cf. (8)):

\section{(8) Tempo $>$ AspPerfeito $>$ AspProgressivo $>$ Voz ... (> V) (CINQUE, 1999: 57)}

Cinque oferece mais evidências para a ordenação dos núcleos funcionais (cf. CINQUE, 1999, cap. 3) para, ao final, mostrar que os advérbios se assemelham aos núcleos funcionais em termos de número, ordem relativa e classes semânticas. Advérbios ocupam, portanto, uma posição de especificadores únicos de núcleos funcionais distintos. Assim, no caso da modalidade epistêmica, tomando como exemplo o inglês, o advérbio probably, se presente na numeração, ocuparia a posição de Spec do modal must 'poder', em seu uso epistêmico.

A assunção da proposta cartográfica de Cinque - para a qual, como vimos, coloca cerca de 30 advérbios no Middlefield - nos leva a repetir a pergunta feita na seção anterior: "Quais AdvPs podem ser utilizados como 'diagnósticos' para a subida do V à flexão? Qualquer AdvP? AdvPs 'baixos', i.e., advérbios normalmente tomados como adjuntos de VP - aqueles que, em termos de hierarquia 
de Cinque, são os mais próximos ao VP -? AdvPs 'altos' (ou sentenciais)?” Na seção seguinte discuto a validade dos AdvPs como diagnósticos para a subida do $\mathrm{V}$ à flexão, trazendo alguns exemplos.

\section{OS ADVÉRBIOS 'BAIXOS’ (OU DE VP)}

Já mencionamos desde o início do texto que a tradição gerativista assume que advérbios baixos (também denominados left-edge adverbs (COSTA, 2008) são diagnósticos confiáveis para o movimento do verbo, por serem adjuntos de VP (ver, para isso, AMBAR, 1989; POLLOCK, 1989; BELLETTI, 1990; GALVES, 1993, 1994; SILVA, 1996; COSTA, 1996, 1998; MODESTO, 2000; SILVA, 2001; BRITO, 1999, 2001; MATOS; CYRINO, 2001; CYRINO; MATOS, 2002; AMBAR et al., 2004; COSTA; GALVES, 2002; COSTA; SILVA, 2006; CYRINO, 2013). Se pensarmos na hierarquia de AdvPs (CINQUE, 1999) - cf. (2) -, esperamos que, uma vez que, em $\mathrm{PB}$, a forma finita do $\mathrm{V}$ temático deve se mover à esquerda do advérbio baixo completamente (cf. (9)), deverá se mover também, em virtude da restrição sobre o movimento nuclear (TRAVIS, 1984), à esquerda de todos os advérbios que seguem completamente na hierarquia, ou seja, deverá necessária e obrigatoriamente se mover à esquerda do AdvP plural completivo (tudo), do AdvP de modo (fluentemente) e do AdvP acelerativo II (cedo). Os dados em (10a,b,c) ilustram o movimento obrigatório de V por sobre esses últimos AdvPs, o que corrobora as previsões da hierarquia:

(9) a. $\quad{ }^{*}$ O João completamente acabou seu trabalho. $\left(\right.$ Asp $\left.p_{\text {SingCompletivo }}\right)$

a' $\quad{ }^{\star} \mathrm{O}$ J. completamente seu trabalho acabou.

b. O João acabou completamente o seu trabalho. (GALVES, 2001: 109)

c. O João acabou o seu trabalho completamente.

(10) a. O João ( ${ }^{\star}$ tudo) fez (tudo) com paciência. (AspplCompletivo)

b. $\quad$ O João ( ${ }^{\star}$ fluentemente) fala (fluentemente) francês (fluentemente) (Voz)

c. O João ( ${ }^{*}$ cedo) acordou (cedo). (Asp Acclerativo(II) $)$

De (9-10), conclui-se também que há movimento obrigatório do V finito, em PB. Do ponto de vista da Cartografia, (9-10) mostram que AdvPs (muito) "baixos" são diagnósticos confiáveis para detectar a subida do V, o que confirma a posição da tradição gerativista acerca do papel dos advérbios baixos ou advérbios de VP na teoria do movimento do V.

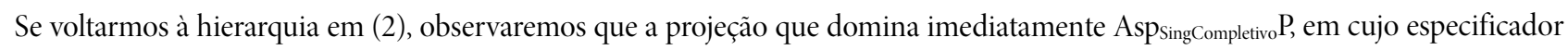
temos completamente, é a projeção "Asp Conativo $\mathrm{P}$ ". Cinque (1999) não identificou um adverbial que, nas línguas românicas, pudesse lexicalizar o conteúdo semântico de tal projeção; identificou, contudo, o núcleo funcional correspondente - o que não nos leva,

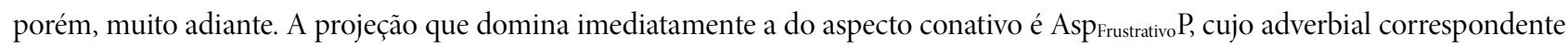
seria à toa/em vão, em PB. Conforme mostra (11), à toa também parece não poder preceder a forma finita do V, o que significa que o movimento do V sobre esse adverbial também é obrigatório:

(11) a. $\quad * / ?$ O José à toa fez seu trabalho

b. $\quad$ O José fez à toa seu trabalho/ O José fez seu trabalho à toa

C-comandando o AdvP frustrativo à toa, temos o de modalidade de raiz obrigatoriamente, que ocupa a posição de [Spec, Mod $\mathrm{Obrigacão]}$ (12a) mostra que o movimento do V finito por sobre esse AdvP não é obrigatório: 
Se modificamos a forma do verbo, como em (13-15), em que temos o V no infinitivo, em uma oração-complemento de odiar/desejar, percebemos que os julgamentos se mantém para o frustrativo à toa e os advérbios por ele c-comandados:
(13) a. * À toa fazer seu trabalho, o João odeia
$($ Asp Frustativo $)$
b. Fazer à toa seu trabalho, o João odeia
(14) a. $\quad{ }^{\star}$ Completamente acabar seu trabalho, o João deseja (Asp $p_{\text {SingCompletive }}$ )
a. $\quad{ }^{\star}$ Completamente seu trabalho acabar, o João deseja
b. Acabar completamente o seu trabalho, o João deseja
c. Acabar o seu trabalho completamente, o João deseja
(15) a. ( $\quad{ }^{\star}$ Tudo) fazer (tudo) com paciência, o João pretende (Asp PlCompletive $)$
b. ( ${ }^{*}$ Fluentemente) falar (fluentemente) francês (fluentemente), a Mara deseja (Voice)
c. $\quad\left({ }^{*}\right.$ Cedo) $)$ limpar (cedo) a casa, o Eduardo odeia (Asp Celerative(II)

Repare, contudo, que obrigatoriamente, o AdvP que precede à toa na hierarquia - e que, portanto, o c-comanda -, dessa vez, i.e., com a forma infinitiva, apresenta comportamento distinto em relação ao $\mathrm{V}$ na forma finita: obrigatoriamente não pode preceder o infinitivo em questão:

(16) a. ${ }^{\star}$ Obrigatoriamente fazer o trabalho, o João detesta

b. Fazer obrigatoriamente o trabalho, o João detesta

Há, então, diferenças em relação à altura que as formas finita e infinitiva do V sobem, em PB, se tomarmos como diagnósticos os advérbios baixos ${ }^{6}$.

Relativamente ao $\mathrm{V}$ no particípio, teríamos de distinguir o particípio passado ativo do passivo, bem como o particípio absoluto (BELLETTI, 1990; CINQUE, 1999). Dadas as limitações de espaço, ilustrarei o movimento do particípio passado ativo, por entre advérbios baixos, nos exemplos a seguir:

O João terá ( ${ }^{*}$ cedo) acordado (cedo) $\left(\right.$ Asp $\left._{\text {Acelerativo(II) }}\right)$

\footnotetext{
${ }^{6} \mathrm{Um}$ dos pareceristas anônimos colocou uma questão muito interessante relativamente à diferença entre formas finitas e não finitas. Há que se perguntar se tal diferença, nas palavras dele, "não poderia estar relacionada à questão da finitude mesma". Na verdade, o verbo na forma finita curiosamente sobe menos, em PB, se considerarmos o movimento obrigatório do V: o verbo infinitivo precisa obrigatoriamente subir mais em PB, necessariamente ultrapassando obrigatoriamente, ao passo que o $\mathrm{V}$ finito deve apenas ultrapassar em vão. A investigação deve ser estendida aos advérbios mediais para se precisar, com clareza, a altura dos movimentos opcionais e verificar se a conjectura apontada pelo colega está correta: é de esperar que, sendo o $\mathrm{V}$ finito dotado do traço [+ tense], ele tenha de se mover mais. Mas, por outro lado, não seria estranho se a forma infinitiva se movesse a alturas mais altas, uma vez que, tendo em vista que o infinitivo é [-tense], o $V$ nessa forma talvez tenha de valorar traços de modo, p.ex., avançando a alturas ainda maiores. Essa questão é bastante intrigante e, no estado atual da investigação, é difícil oferecer uma resposta conclusiva. Por fim, uma vez que parece não haver relação semântica entre a altura do movimento do V e o tipo de forma verbal há que se verificar, como apontado corretamente pelo colega, se as diferentes alturas não teriam "relação com a estrutura da informação".
} 
(17-22), com o verbo temático no particípio, exibem um comportamento diferente do das sentenças (9-16), com a forma finita e infinitiva do V: enquanto essas últimas duas formas de $\mathrm{V}$ obrigatoriamente se movem à esquerda de à toa/em vão, que lexicaliza o aspecto frustativo - o infinitivo sobe, na verdade, um nó acima, ainda, como vimos, movendo-se obrigatoriamente acima do advérbio de modalidade raiz obrigatoriamente -, a forma do particípio passado ativo do verbo deve se mover de maneira obrigatória, em $\mathrm{PB}$, à esquerda de tudo: repare que se o AdvP completamente figura à esquerda do particípio, a sentença é apenas "marginal” (19), mas não agramatical (como acontece com os advérbios c-comandados por completamente em (20-22)). Comportamento semelhante ao do infinitivo - ao menos se considerarmos a subida do $\mathrm{V}$ temático por entre os advérbios mais baixos - tem o V no gerúndio (em subordinadas adverbiais), como se vê nos exemplos seguintes abaixo, em que o verbo deve obrigatoriamente ultrapassar o modal de raiz obrigatoriamente:

(23) ( ${ }^{\star}$ Obrigatoriamente) fazendo (obrigatoriamente) o seu trabalho, o Eduardo agrada a todos (Mod ${ }_{\text {Obrig }}$ )

(24) ( ${ }^{\star}$ Em vão) fazendo (em vão) o seu trabalho, o Eduardo sempre se cansa (Asp Frustativo )

(25) $\quad\left({ }^{*}\right.$ Completamente) acabando (completamente) o seu trabalho, o E. estará pronto aos desafios (AspsingCompletivo $)$

(26) ( ${ }^{*}$ Tudo) fazendo (tudo) com paciência, o E. agrada a todos (Asp PlCompletivo)

(27) ( ${ }^{\star}$ Bem) limpando (bem) o chão, o E. deixa o espaço mais aprazível (Voz)

(28) $\quad\left({ }^{\star}\right.$ Cedo) acordando (cedo), o E. já deixa tudo em ordem $\left(\right.$ Asp $\left._{\text {Acelerativo(II) }}\right)$

Obviamente um exame que leve em conta os advérbios mediais e os altos se faz necessário para detectar as diferenças entre o infinitivo e o gerúndio, i.e., até que altura da hierarquia cada forma verbal deve obrigatoriamente subir. Como estamos considerando apenas os advérbios mais baixos da hierarquia, não é possível detectar tal diferença.

Essa variação no que diz respeito à altura a que diferentes formas do V temático sobe na sequência funcional onde estão "pendurados" os AdvPs parece não ter uma explicação semântica óbvia: se o posicionamento do $\mathrm{V}$ em relação a advérbios de diferentes classes dependesse da semântica do AdvP em questão, esperar-se-ia o mesmo comportamento para a forma finita e infinitiva do verbo relativamente ao advérbio frustrativo, contrariamente aos fatos. (13) e (16), repetidas abaixo, mostram que a forma infinitiva do verbo deve se mover mais do que a forma finita (cf. (11a,b) e (12a,b)), também repetidas abaixo, por conveniência): enquanto o V finito tem de subir à esquerda de à toa (o advérbio frustrativo), a forma infinitiva tem ainda de se mover por sobre obrigatoriamente, necessariamente:
a. $\quad *$ À toa fazer seu trabalho, o João odeia
b. Fazer à toa seu trabalho, o João odeia
a. $\quad * / ? ?$ Obrigatoriamente fazer o trabalho, o João detesta
b. Fazer obrigatoriamente o trabalho, o João detesta
a. $\quad * / ?$ ? J José à toa fez seu trabalho
b. O José fez à toa seu trabalho/ O José fez seu trabalho à toa
a. O João obrigatoriamente fará o seu trabalho
b. O João fará obrigatoriamente o seu trabalho

Se se recorre a uma teoria que propõe que os advérbios sejam adjungidos a projeções na estrutura da oração, tendo em vista uma representação minimalista (cujos átomos seriam as projeções VP, $v$ P, TP e CP), os diferentes julgamentos de (9-28) não poderiam ser explicados a não ser que se recorresse a expedientes ad hoc para esclarecer $(i)$ por que o verbo $V$ deve se mover por sobre $a ̀$ toa e todos os advérbios por ele c-comandados, mas não necessariamente por sobre obrigatoriamente, apesar de todos esses advérbios serem tomados como adjuntos de VP em tais análises; e para (ao menos) descrever (ii) o diferente comportamento das formas do V temático finito e do particípio passado (ativo) e do infinitivo e do gerúndio: de todas as formas do V temático aqui investigadas, em PB, o 
particípio passado ativo é a forma que deve subir menos, ultrapassando o advérbio tudo, necessariamente, com resultados marginais para a ausência de movimento por sobre completamente. $\mathrm{O} \mathrm{V}$ finito tem de se mover obrigatoriamente ainda dois nós acima, ultrapassando em vão. O gerúndio e o infinitivo têm ambos de se moverem pelo menos por sobre obrigatoriamente. Mas um exame ulterior ainda se faz necessário, para determinar as diferentes alturas dos movimentos obrigatórios dessas duas formas verbais ${ }^{7}$. Um tratamento cartográfico desses casos dá conta de pelo menos precisar essas diferenças em termos da posição que cada AdvP ocupa na hierarquia de Cinque. Naturalmente, estudos futuros deverão explicar o porquê de tais diferenças, o que naturalmente não é uma tarefa simples.

Como conclusão parcial, temos o seguinte: (i) há movimento obrigatório do V em PB (conforme já largamente mencionado na literatura aqui citada); (ii) há diferença na altura do movimento a depender da forma do verbo: as formas do infinitivo e o gerúndio devem subir mais; (iii) os advérbios baixos são diagnósticos bons, em PB, para a subida do V a uma projeção da flexão.

\section{E OS ADVÉRBIOS ALTOS?}

Até o momento estamos seguros de que AdvPs baixos são diagnósticos confiáveis para a subida de $\mathrm{V}$ à Flexão. Os dados do $\mathrm{PB}$ apresentados na seção anterior sugerem, à luz da teoria assumida, que, independentemente da forma do $\mathrm{V}$ temático, este deve deixar o domínio lexical e se mover ao Middlefield. Contudo, à medida que o V sobe a projeções mais altas, um paradoxo crucial à teoria do movimento do V vai sendo desenhado, fato já apontado em Tescari Neto (2015): AdvPs altos não podem aparecer à direita de V, quando em posição final (ver (29)), muito embora paradoxalmente possam, se um constituinte os seguir (ver (30)).

(29) *O João mente provavelmente

(30) O José comia provavelmente arroz

Como também mostrado naquele trabalho (Tescari Neto, 2015), advérbios baixos podem figurar em posição sentencial final, sem impor riscos à gramaticalidade da sentença:

O João mente ainda/bem/sempre/etc

Parece ser justo tomar a gramaticalidade de (31) e a agramaticalidade de (29) para sugerir que o V finito não pode se mover à esquerda de AdvPs altos (29), mas apenas à esquerda de AdvPs baixos (31) em PB. ${ }^{8}$

Repare que, se alterarmos a forma do V temático, os julgamentos se mantém:

O João tinha mentido ${ }^{\star}($, ) provavelmente

Fazer seu trabalho ${ }^{*}($,) provavelmente, $\mathrm{o}$ João odeia

Fazendo seu trabalho ${ }^{\star}($, ) provavelmente, $o$ João agrada a todos

\footnotetext{
${ }^{7}$ Pesquisa em andamento, realizada no IEL/UNICAMP, no conjunto das atividades do projeto PIBIC-EM "A formação científica de alunos do ensino médio através da metodologia da gramática gerativa: posição das formas nominais do verbo e cartografia sintática”, apoiado pela PRP/UNICAMP/FAEPEX/CNPq/FAPESP, realizado por Caroba Lopes, Costa e Alves (2019), tem por objetivo determinar justamente as diferentes alturas a que cada uma dessas formas sobe em PB.
}

${ }^{8}$ Repare que (i), a seguir, é gramatical. Sua derivação envolve, entretanto, etapas diferentes das envolvidas em (29). Em (i), o V teria subido a uma posição da flexão, necessariamente abaixo de provavelmente. Na sequência, esse advérbio se moveria a uma posição na periferia esquerda (RIZZI, 1997, 2004), possivelmente [Spec,ModifierP], para valorar o traço criterial de "modificação" associado àquela posição. Após o movimento do AdvP, haveria um movimento massivo do remanescente a uma posição de Tópico, acima daquela à qual o AdvP teria subido: 
mostram, portanto, que, de fato, AdvPs altos não podem figurar em posição sentencial final, a menos que estejam de-acentuados (CINQUE, 1999) - tal qual sugerido, nos exemplos acima, pela vírgula. Sendo assim, a derivação de (30) - pelo menos em $\mathrm{PB}$ - não poderá envolver o movimento de $\mathrm{V}$ por sobre provavelmente, tal qual sugerido em $\left(30^{\prime}\right)$, a seguir.

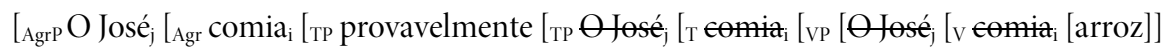

Repare que em $(30 ")$, o advérbio provavelmente não é sequer recuperável pelo VP elíptico, no segundo membro da coordenação, o que significa que a derivação proposta em (30'), envolvendo o movimento do V à esquerda de provavelmente não é, de certo, a opção mais correta.
O José comia provavelmente arroz e a Maria também comia [-]
a. [-]: eemia arroz
b. [-]: ${ }^{*}$ provavelmente arroz

Se a representação em (30'), que envolve o movimento do $\mathrm{V}$ finito por sobre provavelmente, não pode corresponder à derivação correta de (30), em PB, isso significa dizer que o $\mathrm{V}$ finito não se move acima de advérbios altos nessa língua. Noutras palavras, conforme já mostrado em Tescari Neto (2015) para o V finito - ideia ampliada aqui, ao considerar o gerúndio, o infinitivo e o particípio passado ativo -, AdvPs altos não podem ser utilizados, em $\mathrm{PB}$, como diagnósticos para o movimento do $\mathrm{V}$ à flexão e alguma outra alternativa deverá ser oferecida para a derivação de $(30)^{9}$.

\section{6 À GUISA DE CONCLUSÃO}

O objetivo do trabalho foi argumentar que AdvPs de VP (ou advérbios baixos) são diagnósticos fidedignos para o movimento do verbo à flexão, em $\mathrm{PB}$, independentemente da forma do verbo (se finito, infinitivo, gerúndio ou particípio (passado ativo)).

Diferentes formas do verbo sobem a alturas distintas em PB. Assim, o verbo finito deve obrigatoriamente ultrapassar o advérbio de aspecto frustrativo à toa/em vão, mas não o advérbio de modalidade de raiz obrigatoriamente. Já o particípio passado ativo deve se mover pelo menos por sobre tudo, obrigatoriamente - sendo que a ausência do movimento por sobre completamente dá lugar apenas à marginalidade da sentença. O infinitivo e o gerúndio devem se mover acima de obrigatoriamente e todos os outros advérbios que $\mathrm{o}$ seguem na hierarquia. Estudos futuros deverão de alguma forma tentar explicar por que diferentes formas verbais sobem a alturas diferentes mesmo dentro de uma mesma língua.

Em linhas gerais, argumentamos que AdvPs baixos são bons diagnósticos para a subida do $\mathrm{V}$ a posições da flexão. A utilização de AdvPs altos como diagnósticos em PB (fato já discutido em Tescari Neto $(2013,2015)$ e testado, dessa vez aqui, com o gerúndio, o infinitivo e o particípio) não seria, portanto, uma atitude metodologicamente correta.

\section{REFERENCIAS}

AMBAR, M. Sobre a posição do sujeito, movimento do verbo e estrutura da frase. Actas do $5^{\circ}$ Encontro da Associação Portuguesa de Linguística. Lisboa: APL, 1989, p. 369-399.

AMBAR, M.; NEGRÃO, E.V.; VELOSO, R.; GRAÇA, L. Tense domains in BP and EP - vP, CP and phases. In: ABOH, E. et al. (ed.). Romance languages linguistic and theory. Amsterdam: John Benjamins, 2009. p. 1-24. 
BELLETTI, A. Generalized verb movement. Turim: Rosenberg \& Sellier, 1990.

Agreement Projections. In: BALTIN, M.; COLLINS, C. (ed.). The handbook of contemporary syntactic theory. Malden/Oxford: Blackwell Publishers, 2001.p. 482-510.

BOBALJIK, J. Morphosyntax: the syntax of verbal inflection. PhD Dissertation, MIT, 1995.

Floating Quantifiers: Handle with Care. Ms. University of Connecticut, 2001. Disponível em: http://bobaljik.uconn.edu/papers/FQII.pdf. Acesso em: 31 mar. 2019.

BORGES NETO, J. Ensaios de filosofia da linguística. São Paulo: Parábola, 2004.

BRITO, A.M. Concordância, estrutura de frase e movimento do verbo no português europeu, no português brasileiro e no Português de Moçambique. In: FARIA, I.H. (org.) Lindley Cintra: homenagem ao homem, ao mestre e ao cidadão. Lisboa: Cosmos, 1999. p. 332-365.

Clause Structure, Subject Positions and Verb Movement. About the position of sempre in European Portuguese and Brazilian Portuguese. In: D'HULST, Y.; ROORYCK, J.; SCHROTEN, J. (ed.) Romance Languages and Linguistic Theory 1999: selected papers from 'Going Romance 1999'. Amsterdam: John Benjamins, 2001. p. 63-86.

CARDINALETTI, A.; GIUSTI, G. Partitive "ne" and the QP-Hypothesis: a case study. University of Venice WPL, n.1, p.19, 1991. Disponível em: http://lear.unive.it/bitstream/10278/411/1/cardinaletti.pdf. Acesso em: 31 mar. 2019.

CAROBA LOPES, J.; COSTA, J.; ALVES, L. A formação científica de alunos do ensino médio através da metodologia da gramática gerativa: posição das formas nominais do verbo e cartografia sintática. [Projeto de pesquisa de Iniciação Científica (PIBIC-EM) em andamento]. Campinas: PRP/UNICAMP/FAEPEX/CNPq/FAPESP, 2019.

CHOMSKY, N. Syntactic structures. The Hague/Paris: Mouton, 1957.

. Barriers. Cambridge, Massachusetts: MIT Press, 1986.

Lectures on government and binding. Dordrecht: Foris, 1981.

The minimalist program. Cambridge, Massachusetts: MIT Press, 1995.

CINQUE, G. Adverbs and functional heads: a cross-linguistic perspective. University of Venice Working Papers in Linguistics, v.7, n.1, p.2, 1997.

Adverbs and functional heads: a cross-linguistic perspective. New York: OUP, 1999.

. Issues in adverbial syntax. Lingua, v. 114, p. 683-710, 2004.

COSTA, J. Adverb positioning and V-movement in English. Studia Linguistica, 50 (1), 1996, p. 22-34.

COSTA, J. Word order variation: a constraint-baised approach. PhD Dissertation, Leiden University, 1998. . Adverbs and the Syntax-Semantics Interplay. Estudos Linguísticos, v.2, p.13-25, 2008. 
COSTA, J.; GALVES, C. External subjects in two varieties of portuguese: evidence for a non-unified analisys. In: BEYSSADE, C. et al. (ed.). Proceedings of Going Romance 2000. Amsterdam/Philadelphia: John Benjamins, 2002. p. 109-125.

COSTA, J.; SILVA, M.C.F. Notas sobre a concordância verbal e nominal em português. Estudos Linguísticos, v. 35, p. 95-109, 2006, .

CYRINO, S. On richness of tense and verb movement in Brazilian Portuguese. In: CAMACHO-TABOADA, V. et al. (ed.) Information Structure and Agreement. Amsterdam: John Benjamins, 2013. p. 297-318.

CYRINO, S.M.L.; MATOS, G. VP ellipsis in European and Brazilian Portuguese - a comparative analysis. Journal of Portuguese Linguistics, v.1, n.2, p.177-195, 2002.

DOETJES, J. Quantifiers and selection: on the distribution of quantifying expressions in French, Dutch and English. PhD Dissertation, Leiden University/ HAG, The Hague, 1997.

EMONDS, J. The verbal complex V'-V in French. Linguistic Inquiry, v.9, n.2, p.151-175, 1978.

FITZPATRICK, J.M. The syntactic and semantic roots of floating quantification. PhD Diss., MIT, 1996. Disponível em: http://dspace.mit.edu/handle/1721.1/37420. Acesso em: 31 mar. 2019.

FOUREZ, G. A construção das ciências: introdução à filosofia e à ética das ciências. Trad. de Luiz Paulo Rouanet. São Paulo: Editora da UNESP, 1995.

GALVES, C. O Enfraquecimento da concordância no português brasileiro. In: ROBERTS, I; KATO, M. Português brasileiro: uma viagem diacrônica. Campinas: Editora da UNICAMP, 1993.p. 387-408.

- V-movement, levels of representation and the Structure of S. Letras de Hoje, v. 96, p.35-58, 1994.

. Ensaios sobre as gramáticas do português. Campinas: Editora da Unicamp, 2001.

GARZONIO, J.; POLETTO, C. When low are high: on adverb movement in abruzzese. Quaderni di lavoro ASIt, v.17, p. 19-34, 2014.

GIUSTI, G. The Categorial Status of Quantified Nominals. Linguistiche Berichte, v. 136, p. 438-454, 2001. Disponível em: http://dspace-unive.cilea.it/bitstream/10278/748/1/Giusti\%2003.pdf..Acesso em: 31 mar. 2019.

KAYNE, R. Movement and silence. New York: Oxford University Press, 2005.

KOOPMAN, H.; SZABOLCSI, A. Verbal complexes. Cambridge, Mass.: MIT Press, 2000.

LACERDA, R. Quantificadores flutuantes no português brasileiro. Dissertação (Mestrado em Linguística), USP, 2012.

. Rebel without a Case. In: ORDÓÑEZ, F.; KATO, M. (ed.) The morphosyntax of Portuguese and Spanish in Latin America. Oxford: OUP, 2016. 
LAENZLINGER, C. A Feature-based theory of adverb syntax. GG@G (Generative Grammar in Geneva), v. 3, p. 67-105, 2012.

. Elements of comparative generative grammar: a cartographic approach. Padova: Unipress, 2011.

LAENZLINGER, C.; SOARE, G. A cartographic approach to the Romance mittelfeld. Rivista di Grammatica Generativa, v. 30, p. 17-69, 2005.

LARSON, R. K. On the double object construction. Linguistic Inquiry, v.19, p. 335-391, 1988.

MATOS, G.; CYRINO, S.M.L. Elipse de VP no Português Europeu e no Português Brasileiro. Boletim da Abralin, v. 26, special issue, p. 386-390, 2001.

MODESTO, M. On the identification of null arguments. PhD Dissertation, USC, 2000.

POLLOCK, J-Y. Verb movement, universal grammar, and the structure of IP. Linguistic Inquiry, v. 20, n.3, p. 365-474, 1989.

RIZZI, L. Relativized minimality. Cambridge, Mass.: MIT Press, 1990.

The fine structure of left periphery. In: HAEGMAN, L. (ed.). Elements of grammar. Dordrecht: Kluwer Academic Publisher, 1997.p. 282-337.

. Locality and left periphery. In: BELLETTI, A. (ed.) Structures and beyond: the cartography of syntactic structures - v .3. New York/Oxford: Oxford University Press, 2004. p. 223-251.

SANTANA, M. S. A sintaxe do advérbio. Dissertação de mestrado, UFRJ, 2005.

Sintagmas adverbiais como especificadores de projeções funcionais. Linguística, Rio de Janeiro, v.3, n.2, p. 189-202, 2007.

SAUSSURE, F. Curso de linguística geral. São Paulo: Cultrix, 1977.

SILVA, M.C.F. A posição sujeito no português brasileiro: frases finitas e infinitivas. Campinas: Editora da UNICAMP, 1996.

SILVA, G. V. Word order in Brazilian Portuguese. Berlin: Mouton de Gruyter, 2001.

SILVA, C. R. T.. Morfologia flexional e movimento do verbo em português: por uma análise unificada a partir da proposta vickneriana. Revista do GELNE, v. 11, p. 1-18, 2009.

SPORTICHE, D. A theory of floating quantifiers and its corollaries for constituent structure. Linguistic Inquiry, v.19, n.3, p. 425$449,1988$. 
TESCARI NETO, A. On verb movement in Brazilian Portuguese: a cartographic study. Tesi (Dottorato di Ricerca in Scienze del Linguaggio), Università Ca' Foscari, 2013.

. Por que advérbios altos não são diagnósticos para o movimento do verbo? Lingüística, v. 31-32, p. 27-46, 2015.

TOSQUI, P.; LONGO, B. A distribuição dos advérbios modalizadores na senteça: uma análise de base gerativa. Alfa, v.47, n.1, p. 85$97,2004$.

TRAVIS, L. Parameters and effects of word order variation. 1984. PhD (Dissertation) - MIT, 1984.

VICENTE, H. S. G. O Quantificador flutuante 'todos' no português brasileiro e no inglês: uma abordagem gerativa. Tese de Doutorado, UnB.

VICENTE, H. G.; QUADROS GOMES, A. Um tratamento unificado de grau para o quantificador flutuante e o intensificador todo. Linguística, Rio de Janeiro, v. 9, p. 112-132, 2013.

\section{(ㅇ) (1) $\circledast$}

Recebido em 20/09/2018. Aceito em 15/02/2019. 